\title{
SAND MANAGEMENT APPROACH FOR A FIELD WITH HIGH VISCOSITY OIL
}

\author{
Maxim Borisovich Grigorev, Dmitry Sergeevich Tananykhin*, Maksim Aleksandrovich Poroshin \\ Saint-Petersburg Mining University, Russian Federation
}

Oil production from weakly consolidated sandstone wasn't needed for decades, but as the time goes on, traditional oil reserves deplete and possibility of these reserves being produced is growing up. In the case of high viscosity oil, located in such reservoir, problem gets even worse. Traditional sand control methods cause lower production rates, thus, making production not profitable enough. In the industry there was need for new approach and it appearedsand management. Sand management is a risky business, but it allows some reservoirs to be produced with good enough profit. But with right amount of preparations risk can be minimized and production becomes more likely. One of the most promising instruments of sand management is chemical treatment with UTTA. It allows to sand particles and fines to be held in the reservoir so they won't cause so much erosion and won't plug pore throats and filtration channels.

Key words: high viscosity oil, weakly consolidated sandstone, poorly consolidated sandstone, sandstone arch, sand fines, fines migration, chemical treatments

\section{INTRODUCTION}

Amount of high viscosity oil, located in weakly consolidated sandstone is estimated at around 600 millions of ton, which is equal to $9.4 \%$ of total high viscosity oil reserves in Russia. Producing high viscosity oil from weakly consolidated sandstone is associated with heavy consequences for reservoir and for surface and subsurface equipment. Most problems are being caused by sand influx into the well, which leads to equipment erosion, bottom-hole collapses and may result in well control incident. A lot of researches were made for accompanies of this problem - petrophysical, rheological and hydromechanical papers give wide performance about it (Hall, 1970; Naveed, 2009; Ivšinović, 2018; Vieira and Jureszik, 2019).

\section{APPROACHES FOR SAND PRODUCTION}

First approach issand control methods. Their purpose is to minimize sand influx into the well, thus solving the problem at the very beginning. Here are we have gravel packing, screens, chemical consolidation, slotted liners and other special filters. The drawback of all this methods is significant permeability decrease (Lakshmi, 2000). In the case of high viscosity oil, which production rate is already lowered by rheological properties, permeability decrease may result in non profitable production rates.

Traditional Russian approach implies minimization of extracted sand while producing oil from weakly consolidated sandstone by using filters, chemical consolidation of near-wellbore zone, gravel packs, screens and other technologies. Nevertheless there are many papers suggesting a new approach - sand control management (King, 2009; Kuncoro, 2001; Tronvoll, 2001; Voronkova et al., 2019; Xavier et al., 2019).

*Tananykhin_DS@pers.spmi.ru
Sand control management is all about monitoring of production and making targeted solutions to maintain stable zone in reservoir. The key point of sand control management is that it allows some volumes of sand to be produced from reservoir and not preventing it completely, as in traditional approach. Sand management practice also shows good results in both economical and technical terms through controlled sand production instead of total exclusion (Andrews, 2005). It's obvious that sand management also has some drawbacks, as shown in work (Dusseault, 2000):

1. Massive erosion

2. Need for sand removal and separationis much higher.

3. Potential risk of well control incident

4. Sand monitoring techniques and hardware

On the other side, sand management has huge benefit in well's productivity and in reduction of completion cost (Dusseault, 2000). For example, as consequence of implementing sand management to Statfjord oilfield was 2 million barrels increase in oil production and 4 millions to Gullfaks for the same amount of time (Andrews, 2005).

That was the case of not viscous oil. As for high viscosity oil (with viscosity $>20 \mathrm{mPa}^{*} \mathrm{~s}$ ), sand volumes grow dramatically, so sand management in this case is difficult to apply (Figure 1).

Sand management is also inappropriate if porosity is lower than $20 \%$, because porosity correlates with sand cementation. Thus, porosity lower than $20 \%$ means that sand is well cemented and sand management isn't necessary.

Key process to enhance oil recovery from such reservoirs is to solve suffusion problem and also sand-influx from near-wellbore zone, because both these problems 


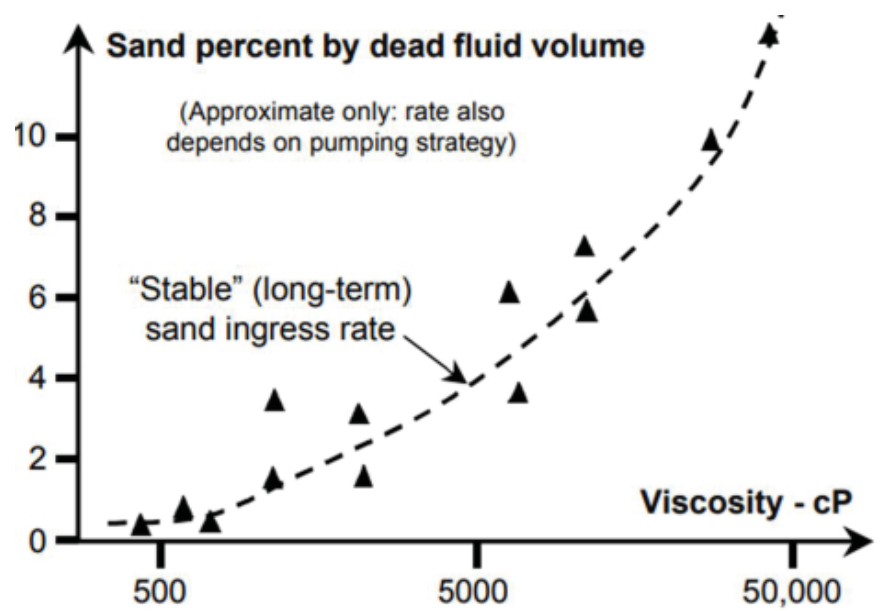

Figure 1: Dependence of sand influx from oil viscosity in vertical wells (Dusseault, 2000)

may cause some significant incidents(Ke, 2016; Goloshchapova, 2018; Rahman, 2017). If there is high viscosity oil in the reservoir, problem gets even worse, because hydrodynamic force of such oil is much higher than of traditional one, so it's much easier for it to capture sand grains (fines) and pull them out of reservoir (Zheng, 2019).

\section{DIVINATION ON SAND PRODUCTION}

First of all, if we found out, that we have oilfield in weakly consolidated sandstone, we have to predict sand production volumes or make some models to ensure that we won't have collapses in reservoir.

There are many factors that lead to reservoir failures and sandstone weakening - drilling operations, cyclic effects of shut-in and start-up, operational conditions, reservoir pressure depletion, and strength-weakening effect of water and others (Rahmati, 2012). High pressure gradient due to fluid flow also facilitates the detachment of sand particles. In addition, fluid flow is responsible for the transport and production of cohesionless sand particles or detached sand clumps to the wellbore. Sand production depends on many factors, such as stress redistribution around the wellbore, properties of the rock and fluids in the reservoir, and the completion type.

To predict all the points that need to be investigated, it is highly recommended to get as many core samples as possible (considering costs) to get full representation of reservoir properties and conditions (Rahmati, 2012). After gathering all the samples, it is likely to send them to laboratory to get data out of them. Then some other methods can be used (sound logging, log property mapping, finite element method analysis etc.).

There are 3 main ways to predict sand production:

1. Laboratory tests, but they are mostly useless and only help if you want to know the onset of sand production. They are also restricted by the observation area, which is diameter of the well in the case of core samples and it's too small to make right and reliable predictions.
2. Analytical models can also predict the onset of sand production and then can be used to capture the mechanism of sanding under simple conditions (which oil reservoirs isn't). Due to their simplicity, these methods may be used to get approximate representation in-situ.

3. Numerical models are the most useful due to their complexity and ability to predict many factors - volumes of sand production, sanding onset, permeability decrease and etc. Drawback is the complexity of implementation because they need high computing powers to work stable.

After studying all the models we choose whether or not we should use sand management methods. In most cases it's likely to use them, because implementing of sand production management may result in $36 \%$ oil flow rate increase (King, 2009). This information is quite optimistic, but there are no confirmations of such increases on other oilfields. On the other hand, there is a work that alters previous statementby saying that any kind of sand control or management leads to lowering production rates, but there are no signs of data from production sites (Matanovic, 2012).

In the case of weakly consolidated sandstones, there is some cementing material in the reservoir, so production might start without sand-influx at the first time. As the time goes on, some sand is being produced from wellbore zone, which due to rock dilation leads to porosity increase from 30 to $40 \%$ and furthermore -3 fold permeability increase due to increased porosity, but this is only for bottomhole zone. In fact, permeability might even decrease due to disaggregation of sand in the reservoir, plugging of the pore space and sand deposition(King, 2009). So it's more likely to let these newly formed cracks to be there and provide good production rates for the well. This means that any kind of filter, screen, chemical consolidation operations will:

1. Not let these cracks to form

2. Decrease permeability on the side of the well

All of the above means, that to support high production rates there are must be some natural filtration, that won't let too much sand-influx into the well.

\section{INVESTIGATION OF THE MICROPROCESSES IN THE RESERVOIR}

During the experiments with perforated casings, some researchers mentioned that flowing process near these perforations is conjugated with forming of "archs". These structures work as a natural filter, not letting mass suffusion process to occur.

Process of arch's forming is connected with the pressure from flow and natural packing of sand particles near perforation holes (King, 2009). There is contradiction between some authors, because some of them state that arch's are stable due to capillary forces, when sand grains are wetted by water and others state that it's pos- 


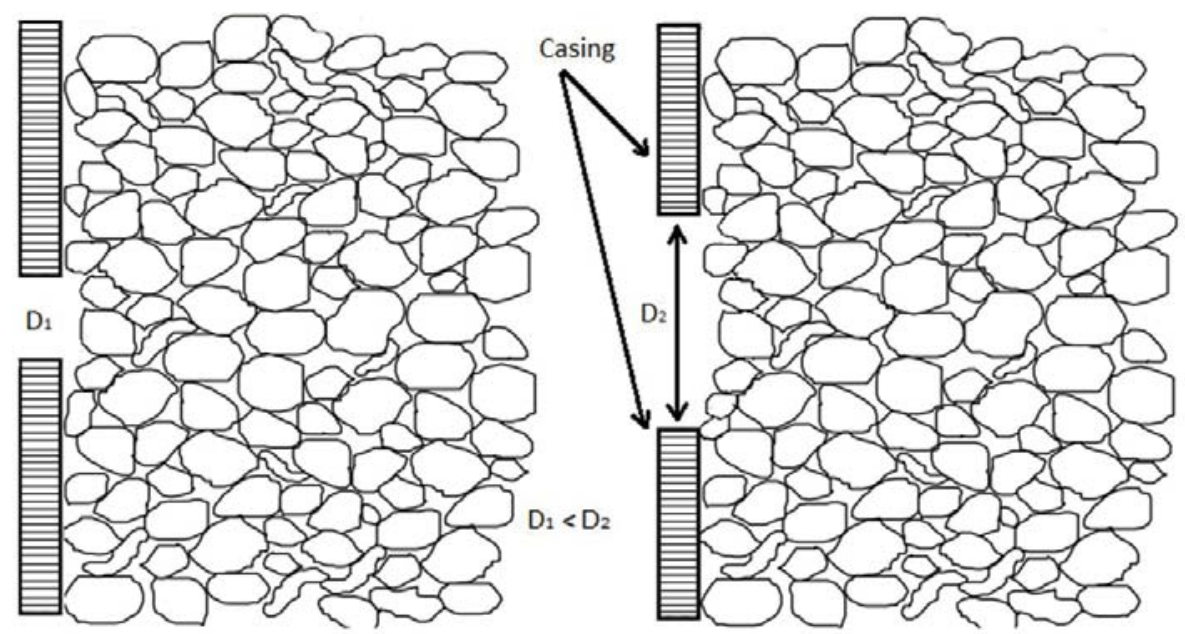

Figure 2: Formation of arch structure in reservoir near perforation hole

sible due to pressure from fluid that's flowing between cracks and pores in the reservoir (Matanovic, 2012). The second one is more likely to be true, because there are some evidences (King, 2009; Kuncoro, 2001) that archs are forming and deforming depending on the fluid flow pressure in the reservoir. Even air can support high enough pressure flow to sustain arch's stability (Hall, 1970). Arch's stability also depends on the grains form, size and distribution in the reservoir. There is a research that recommends using uniform, rounded quartz sand with narrower perforation holes in casing to ensure better sustainability conditions for archs. That is obvious due to necessity of filter cake in the form of arch to be near perforation hole. Size of these arch's is a function of production rate, and there is straight line dependency with increase in production rate grows size of arch. Thus, with the size of an arch grows intergranular distance and permeability increases.

Increased integranular distance leads to a massive problem - fines migration. Fines aresmall particles with diameter ranging from 0.1 to 30 microns. With increased intergranural distance it is more likely for fines to influx the well, which will cause stress redistribution and reservoir failure in the future (Christianti, 2011).

Fines migration causes such problems as:

1. Productivity impairment due to plugging of proppant pack;

2. Screen erosion, hence loss of sand control;

3. Groundequipment erosion.

Fines migration process is triggered by:

1. Fluid velocity;

2. Wettability alteration;

3. Change of $\mathrm{pH}$ in reservoir (normal $\mathrm{pH}$ value is $>4$ and $<7$ );

4. Matrix acidizing ;

5. Temperature.

Fines, that create filter cake cause permeability reduction on the order of 15 to $30 \%$ following throughput of only 100 pore volumes of liquid at high velocity, according to laboratory experiments (Gruesbeck, 1982). As in the case of the formation of arched structures, brief reversal of flow after continuous production causes re-establishment of original permeability, then resulting in decline in permeability again. This process is caused by dislodging of plug deposits followed by redeposition of fines once again. This method can be used to quickly check rather production drop is caused by fines plugging filter or not.

Fluid velocity is the key point that triggers fines migration process. There is a critical velocity (flow rate), below which entrainment of fines may not happen, if fluid is onephased. In the presence of two phase flow, fines tend to migrate because fines are normally water wet and water ingress into the reservoir will cause fines migration process easier. Turbulence in multiphase flow will make this problem more severe and the critical velocity is usually smaller in two phase flow (Xiao, 2017). Increase in flow rate results in stronger entrainment of fines and results in straight-line dependency of amount of fines dragged by fluid from fluid's velocity (Gruesbeck, 1982).

\section{PROPOSALS FOR SUSTAINABLE SAND PRODUCTION}

So, effective way to increase oil recovery ratio and to do it efficiently (in economical terms) is to solve fines migration problem without using filters, screens and other sand control methods. After solving this problem, some measures can be taken with sand production.

There are some possible solutions to preserve fines migration problem:

1. Injection of organosilane-polymeric chemical compositions

2. Using retarted HF systems

3. Pore throat enlargement

4. UTTA (ultra-thin trackifying agent)

Main effect of organosilane systems is increasing adhesion force in reservoir, it may result in fines being hold in by rock, thus, not letting them to invade near-wellbore zone(Christianti, 2011). In the studies made by Schlum 
berger they used to inject this agent with water into the near wellbore zone, but there is no point whether it is injected separately or as an additive to the injection water, thus distributing this agent in the reservoir. It may have significant effect, because changing from one-phase fluid to two-phase makes it easier for fines to be produced (Gruesbeck, 1982).

Under most circumstances, fines migration occurred deep in the formation and any chemical solution must be designed to be functioning retarded as far from the wellbore as possible. All systems produce precipitation in contact with clays(Galal, 2016).

There are 3 most used retarted HF systems:

1. Boron ion systems - doesn't work in formations that contain illite or K-feldspar because there is no reaction with quartz (Xiao, 2017)

2. Aluminum ion systems - made to keep low pH in reservoir (Galal, 2016)

3. Phosphorus complex systems - even though they have the highest dissolving power of silica and clays and can dissolve products without precipitation for much time, it's quite expensive (Xiao, 2017)

Cementing material of sandstone is a key factor that's holding together pieces of sand in the formation, so any acid treatment may result in dissolving of this material and further increasing of amount of fines in the flow. But formation also has a benefit from an acidizing - pore throat enlargement. Thus, at the cost of an increased amount of fines in the flow, an increase in oil flow to the well and increased amount of channels in the reservoir is achieved. There are also studies that show that fines will not bridge near the pore throat if the average pore size of the formation is greater than the critical range ( $1 / 7$ to $1 / 3$ of the size of average fine), in other words - permeability increase is achieved by unplugging of some pore throats but it's unstable due to increased amount of fines in the flow(Xiao, 2017).

UTTA is commonly used after acidizing treatments. It is used mostly to keep fines that have accumulated from this procedure in place so they won't migrate with the fluid. Retention is achieved by creating a thin film that holds these fines in it. This film is distributed in the formation by the natural force of capillary pressure. UTTA is also durable so it can hold fines even with high flow rates, but will it work with high viscosity oil, whose flow rate is slow, but enthralling ability is stronger than of traditional oil (Xiao, 2017).

\section{CONCLUSION}

High viscosity oil production from weakly consolidated sandstone is tightly connected with two moments:

1. Pore throat plugging (also actual for filter throats plugging)

2. Equipment breakdowns, natural flow stopping, well control accidents etc.
Traditional approach for oil production from sandstone is all about filters and chemical consolidation, whose main problem is permeability lowering in near-wellbore zone. Thus, production becomes not commercially viable. To increase profitability from production in these conditions industry needed a new approach - sand management methods.

These methods contribute to saving natural filtration parameters of reservoir (porosity, permeability etc.) and furthermore increasing production rates. Presently, there are no standard methodology for sand management usage, but there are some articles in journals about this problem that suggest bits of useful information. Main elements that worth mentioning are:

1. Individual approach for each well

2. There are need for thorough research with core samples, laboratory studies, modeling with computer powers.

3. Accounting of oil's enthralling properties

4. Complex analysis of near-wellbore zone to forecast local breakout points, breakdown possibility of borehole zone,

5. Accounting of lesser sand particles and fines for filters, screens and other sand control techniques.

There is not that much researches about archs properties and fluid's enthralling force measurements. Most of experiments were made just to see these structures and to check whether or not there are any special moments that should be investigated in the future(Goloshchapova, 2018; Ermakova, 2016). There is a publication with a big amount of experiments (Musaed, 1999), but they are not viable in Russian conditions (and most of others) due to very high porosity (around $45 \%$ ) and a very low viscosity $(1.05 \mathrm{cp})$ in this series, so there is necessity of new experiments with more viscous oil and less porous rock. Their conclusion is impossibility of sand production control via controlling flow rate (because flow rate affects drag force of the flow), but drag force also depends on viscosity, so the key point is to find a balance between flow rate and viscosity to decrease drag force as much as possible.

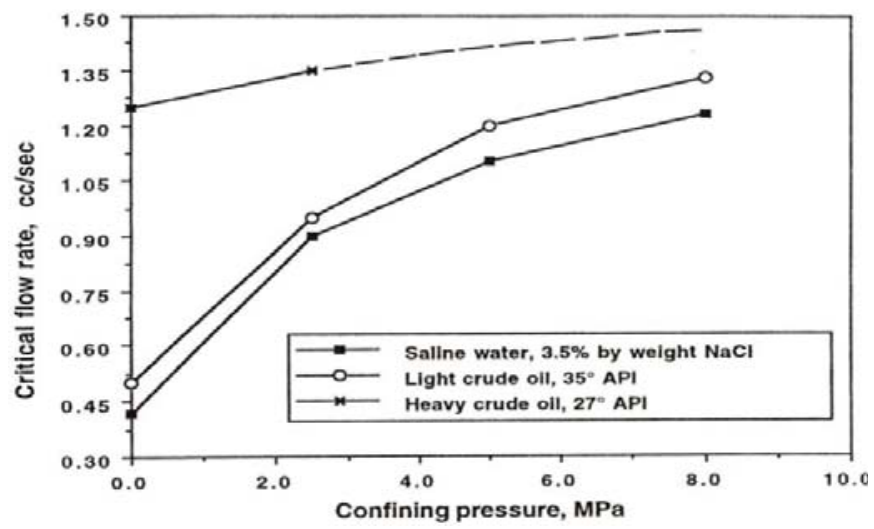

Figure 3: Relationship between critical flow rate and confining pressure (Musaed, 1999) 


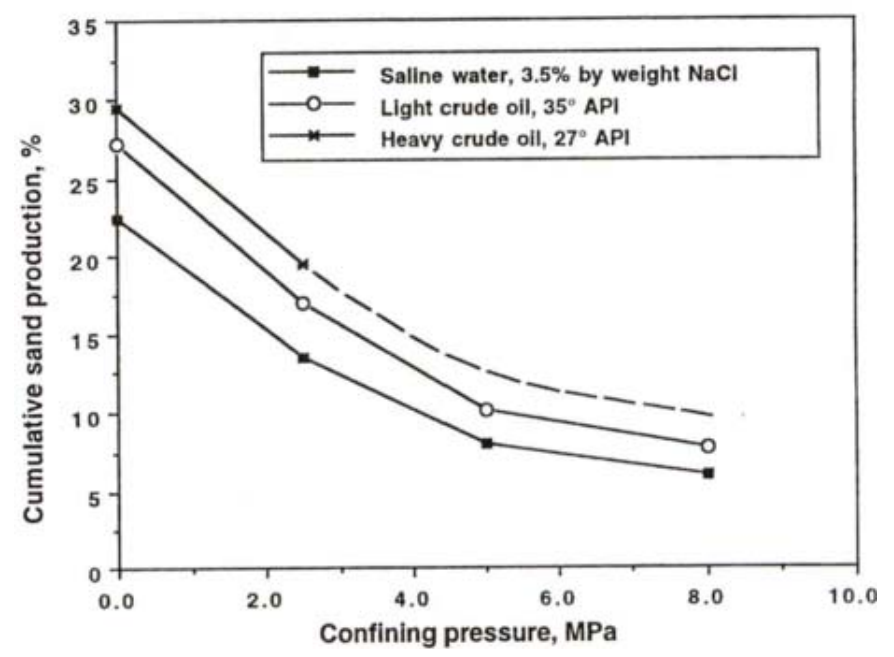

Figure 4: Relationship between cumulative sand production and confining pressure (Musaed, 1999)

Major problem of sand management is sand fines production with oil. They aren't only causing massive erosion for equipment, but they also plug many filtration channels in the reservoir and near-wellbore zone, thus, decreasing production rate. One of the most usable treatments to solve this problem is UTTA injection in the reservoir. There are no publications with chemical formula or any other useful information about its properties or pros and cons, but it's seen as one of the most perspective methods to solve this problem completely.

\section{REFERENCE}

1. Andrews J., Kjorholt H. et.al. (2005). Production enhancement from sand management philosophy. A case study from Statfjord and Gulfaks. SPE 6th European Formation Damage Conference, 12-18.

2. Christianti Y., Giovanni F. et al. (2011).A new technique to control fines migration in poorly consolidated sandstones - laboratory development and case histories. SPE European Damage conference,13-17.

3. Clay G.,Collins R. (1982).Entrainment and Deposition of Fine Particles in Porous Media. Society of Petroleum Engineers Journal, 22,47-56.

4. Dusseault M.B.,Tronvoll J. et.al. (2000).Skin self-cleaning in high rate oil wells using sand management. SPE International Symposium on Formation Damage Control, 12-16.

5. Goloshchapova L.V., Plaskova N.S., Prodanova N.A., Yusupova S.Y., \&Pozdeeva S.N. (2018). Analytical review of risks of loss of profits in cargo transportation. International Journal of Mechanical Engineering and Technology, 9(11), 1897-1902.

6. Ermakova A.N., Vaytsekhovskaya S.S., Malitskaya V.B., Prodanova N.A. (2016).Investment attractiveness of small innovational business under the conditions of globalization and integration. European Research Studies Journal, 19(2 Special Issue), 258267.
7. Galal S.K. et.al. (2016).Formation damage due to fines migration and its remedial methods. Egyptian Journal of Petroleum, 25,63-72.

8. HallC.D.,HarrisbergerW.H. (1970).Stability of sand arches: a key to sand control. Journal of Petroleum Technology, 22,92-99.

9. Hossein Rahmati, MahshidJafarpour et al. (2013). Review of sand production prediction models. Journal of Petroleum Engineering, 3, 42-58.

10. Hoffmann, M. (2017). An exploratory study: Mobile device use for academics. Research in Social Sciences and Technology, 2(1), 18-52.

11. Ivšinović J., Pleteš V., Marinić M. (2018).Production of hydrocarbons from weakly consolidated sandstone reservoirs in the Croatian part of the Pannonian basin system. Journal Mining of mineral deposits, 12(2), 114-119.

12. Ke, Lin, Ouyang, Mao, Horikoshi, Kazuki, Takahashi, Akihiro. (2016).Soil deformation due to suffusion and its consequences on undrained behavior under various confining pressures. Japanese Geotechnical Society Special Publication, 114-119.

13. King G.E. (2009).Engineering company. Sand control overview. Houston, 37-46.

14. Kuncoro B., Ulumuddin B.et al. (2001). Sand control for unconsolidated reservoirs. National symposium IATMI, 82-89.

15. Lakshmi N. Reddi, Xiao Ming et al. (2000).Permeability reduction of soil filters due to physical clogging. Journal of geotechnical and geoenvironmental engineering, 29-40.

16. Matanovic D., Cikes M. et al. (2012). Sand control in well construction and operation. Springer Environmental Science and Engineering series of books, $224 \mathrm{p}$.

17. Musaed N.J.,Al-Awad, Abdel-Alim H. El-Sayed, Saad El-Din M. Desouky. (1999).Factors Affecting Sand Production from Unconsolidated Sandstone Saudi Oil and Gas Reservoir. Journal of King Saud University - Engineering Sciences, 11(1), 151-172.

18. Naveed, Akhtar, Adnan, Qazi, Mumtaz, Ahmad M., Farzana, Kalsoom. (2009).Rheological Studies and Characterization of Different Oils. Journal of Chemical Society of Pakistan, 31, 57-63.

19. Rahman, P. A. (2017). Using a specialized Markov chain in the reliability model of disk arrays RAID-10 with data mirroring and striping. IOP Conference Series: Materials Science and Engineering, 177(1). https://doi.org/10.1088/1757-899X/177/1/012087

20. Tadeu, P., Fernandez Batanero, J., \&Tarman, B. (2019). ICT in a Global World. Research in Social Sciences and Technology, 4(2), i-ii. Retrieved fromhttps://ressat.org/index.php/ressat/article/view/431 
21. Tarman, B. (2018). Editorial: 2018 (3)2. Research in Social Sciences and Technology, 3(2), i-ii. Retrieved from http://ressat.org/index.php/ressat/article/view/370

22. Tronvoll J., Dusseault M.B. et al. (2001). The tools of Sand Management. SPE Annual Technical Conference and Exhibition, 91-107.

23. Voronkova, O., Yankovskaya, V., Kovaleva, I., Epishkin, I., lusupova, I., \&Berdova, Y. (2019). Sustainable territorial development based on the effective use of resource potential. Entrepreneurship and Sustainability Issues, 7(1), 662-673. doi:10.9770/ jesi.2019.7.1(47)

24. Vieira, D. G., \&Jureszik, K. A. (2019). Use of nanostructured curcumine systems as nutraceutical: Bibiliographic review. (UTILIZAÇÃO DE SISTEMAS NANOESTRUTURADOS DE CURCUMINA COMO NUTRACÊUTICOS: REVISÃO BIBILIOGRÁFICA) PeriodicoTcheQuimica, 16(31), 67-73.
25. Xavier, N. S., Xavier, J. R. M., \& Costa, J. A. (2019). Chemical composition of ap-ma-05 archaological site soil in macapá-amapá. (Composiçãoquímica dos solos dos sítiosarqueológicos AP-MA-05 emMacapá-Amapá)PeriodicoTcheQuimica, 16(33), 889902.

26. Xiao J, Wang J, Sun X. (2017).Fines Migration: Problems and Treatments. Oil Gas Res, 3 (1), 37-41.

27. Zheng H., Zhang Y., Zhongxuan Y. (2019).Suffusion-induced deformation and microstructural change of granular soils: a coupled CFD-DEM study. Acta Geotechnica, 64-78. 